\title{
QUALIDADE DA INFORMAÇÃO AMBIENTAL VERSUS RENTABILIDADE DE EMPRESAS DO SETOR ELÉTRICO LISTADAS NO ISE
}

\author{
Quality of environmental information versus profitability of electric \\ industry firms listed in ISE
}

Ana Lúcia dos Santos

E-mail: analucia.santos@ufersa.edu.br

Especialista em contabilidade e Planejamento Tributário pela Universidade Federal Rural do Semiárido; Bacharel em Ciências Contábeis pela Universidade Federal Rural do Semi-árido;

Endereço para contato: Rua General Péricles, 176, 59625-060, Ilha de Santa Luzia, Mossoró, Rio

Grande do Norte, Brasil.

http://orcid.org/0000-0002-5837-0544

Alexsandro Gonçalves da Silva Prado

E-mail: alexsandro.prado@ufersa.edu.br

Mestre e Bacharel em Ciências Contábeis pela Universidade Federal da Paraíba; Professor assistente na Universidade Federal Rural do Semi-árido.

http://orcid.org/0000-0002-7072-3621

Caritsa Scartaty Moreira

E-mail: caritsa_scarlaty@hotmail.com

Mestre em Ciências Contábeis pela Universidade Federal do Rio Grande do Norte; Especialista em Contabilidade e Planejamento Tributário pela Universidade Federal Rural do Semi-árido; Professora

do Magistério Superior. http://orcid.org/0000-0003-1243-9216

José Mauro Madeiros Veloso Soares

E-mail: jose-mauro-m@hotmail.com

Mestre em Ciências Contabéis pela Universidade Federal do Rio Grande do Norte;

Especialista em International Financial Reporting Standards e Normas Brasileiras de Contabilidade pela Universidade do Estado do Rio Grande do Norte; Professor do Magistério Superior.

http://orcid.org/0000-0002-9277-8316

Artigo recebido em 17 de setembro de 2019. Aceito em 26 de outubro de 2020. 


\section{Resumo}

A teoria dos stakeholders presume que os investimentos socioambientais resultam melhor desempenho financeiro, visto que refletem a preocupação da empresa com o meio ambiente e a sociedade. $O$ presente estudo objetivou verificar a relação existente entre a qualidade da informação ambiental e a rentabilidade de empresas do setor de energia elétrica pertencentes ao Brasil Bolsa Balcão (B3) listadas no Índice de Sustentabilidade Empresarial (ISE). A amostra compreendeu 10 empresas brasileiras com ações negociadas na B3 no período de 2014 a 2017. Quanto à coleta de dados, utilizou-se: o Relatório de Sustentabilidade, o modelo Global Reporting Initiative (GRI), as Demonstrações Financeiras Padronizadas (DFPs) e informações econômico-financeiras extraídas no banco de dados do Sistema Economática ${ }^{\circledR}$. A partir dos resultados evidenciou-se que as empresas têm o grau de acurácia médio ou alto, indicando boa qualidade de evidenciação. Ao aplicar a técnica estatística de regressão quantílica, percebeu-se que um maior nível de evidenciação dada pelo índice de acurácia não está associado às variáveis Lucros antes de Juros, Impostos, Depreciação e Amortização (EBITDA), Lucro antes do Imposto de Renda + Disponibilidade Financeira Líquida (LAIR+DLF), Margem Bruta, Earnings Before Interest and Taxes (Margem EBIT), Margem Ebitda, Rentabilidade do Ativo (RentAt) e Retorno sobre o Investimento (ROIC). No geral, os resultados indicaram a inexistência de relação entre a rentabilidade das empresas e as ações socioambientais.

Palavras-chave: Qualidade da informação. Relatório de sustentabilidade. Rentabilidade. Ambiental.

\section{Abstract}

According to the stakeholder theory, social and environmental investments are supposed to result in better financial performance, as these investments reflect the company's concern about the environment and society. This study aimed to verify the relationship between the quality of environmental information and the profitability of electric power companies quoted on the Brazilian stock exchange (B3 S.A.) and listed in the Corporate Sustainability Index. The sample consisted of 10 Brazilian companies with shares traded on B3 S.A. from 2014 to 2017. For the data collection, it was analyzed the company's sustainability report, the Global Reporting Initiative (GRI) model, Standard Financial Statements, and the economic-financial information from the Economática ${ }^{\circledR}$ database. The results show that the companies have medium or high level of accuracy, indicating good quality of disclosure, and the application of the quantile regression technique showed that a higher disclosure given by the accuracy index is not associated with the following variables: Earnings Before Interest, Taxes, Depreciation And Amortization (EBITDA), Earnings Before Income Tax + Net Financial Availability, Gross Margin, Earnings Before Interest And Taxes (EBIT margin), Ebitda margin, Return on assets, and Return on Investment (ROI). The results show no relation between the profitability of the companies and the social and environmental actions.

Keywords: Quality of information. Sustainability report. Profitability. Environmental.

\section{INTRODUÇÃO}

A partir da Segunda Revolução Industrial (1860-1900), a humanidade passou a utilizar de forma intensiva e generalizada a energia elétrica. Carneiro et al. (2012) relatam que no século XXI o setor de energia elétrica se defrontou com um grande desafio: garantir 
o fornecimento de energia elétrica para um mercado de consumo crescente por um preço justo para seus consumidores, almejando, sincronicamente, equilíbrio entre a mitigação da emissão de gases de efeito estufa e o retorno econômico-financeiro das empresas do setor.

A preocupação com o emprego de recursos naturais e com a preservação do meio ambiente por parte do stakeholders atuou como um dos incentivos para as empresas divulgarem informações ambientais de forma voluntária em seus relatórios anuais. Além dos relatórios obrigatórios - Demonstrações do Resultado do Exercício (DRE), Demonstração do Valor Adicionado (DVA), Balanço Patrimonial (BP), Notas Explicativas (N.E) denominadas Demonstrações Financeiras Padronizadas (DFPs) -, as companhias deram início à descrição de sustentabilidade, corroborando os pressupostos da Teoria da Legitimidade (Rover et al., 2012).

A divulgação socioambiental no Brasil ainda é facultativa e não há padrões globais determinados para a elaboração de relatórios de sustentabilidade, todavia há diretrizes bemestruturadas e em desenvolvimento, como as emitidas pela organização Global Reporting Initiative (GRI), que representa o padrão de relatório de sustentabilidade mais disseminada internacionalmente cujas orientações têm sido amplamente adotadas por empresas do globo (Lozano, 2013).

Ressalta-se que para haver um acompanhamento simultâneo dos aspectos socioambiental e econômico as empresas do setor de energia elétrica do Brasil usam modelos de gestão, certificações e orientações nacionais e internacionais (Braga et al., 2011). Segundo a Agência Nacional de Energia Elétrica (ANEEL, 2006), as instituições que compõem este setor, sejam elas concessionárias, seja elas permissionárias, desde o ano de 2006 são obrigadas a elaborar o Relatório de Responsabilidade Socioambiental. O GRI dispõe de um grupo de indicadores específicos para o âmbito de energia elétrica, que englobam aspectos econômicos, sociais e ambientais. A partir desses indicadores, a ANEEL elaborou um conjunto de orientações para a elaboração do relatório socioambiental, aperfeiçoando a avaliação da divulgação socioambiental no setor em realce (ANEEL, 2006).

De acordo com Rosa et al. (2011), mediante a divulgação socioambiental os usuários da informação - acionistas, sociedade, governo, entre outros - analisam o posicionamento das empresas sobre a preservação do meio ambiente. Assim, a divulgação ambiental é empregada como ferramenta de prestação de contas com os usuários da informação. Há um grande movimento de caráter social e científico para que se estimule a avaliação das informações ambientais, ou seja, fomentá-la nas comprovações, procurando, desse modo, um equilíbrio entre os elementos econômico e socioambiental que compõem as dimensões do desenvolvimento sustentável.

No ano de 2005, foi implementado pela B3 o Índice de Sustentabilidade Empresarial (ISE), com o intento de reunir empresas que se destacam entre as 200 com ações mais líquidas, tendo como medida tornar seus negócios sustentáveis. Ainda, utilizado para 
a análise comparativa do desempenho de empresas listadas na Bolsa sob o aspecto da sustentabilidade corporativa, fundamentado em eficiência econômica, equilíbrio ambiental, justiça social e governança corporativa (BM\&FBovespa, 2019).

Esse Índice evidencia as empresas que estão comprometidas com a questão da sustentabilidade e serve como guia para os investidores que pretendem fazer parte da carteira de ações com empresas que apresentam rentabilidade e geram dividendos, mas que também sejam envolvidas com aspectos socioambientais e governança corporativa. Segundo Fasolin et al. (2014), cada vez mais pressionadas pela sociedade, essas instituições visam, além da dimensão econômica, desempenho adequado na visão socioambiental. Ademais, a responsabilidade socioambiental sinaliza aos consumidores, investidores e reguladores a forma como devem operar para mitigar a degradação ambiental (Darnall \& Carmin, 2005) e desenvolver uma consciência de reputação ambiental, atuando como meio na avaliação feita por compradores, acionistas, governo e sociedade. Esse comportamento é pautado pelos fundamentos da teoria da sinalização, que tem como propósito resolver problemas de desequilíbrio de informações (Spence, 1973).

A Teoria da Legitimidade considera a inter-relação entre as empresas e a sociedade na qual atua. Nessa perspectiva, o relatório de sustentabilidade é um importante instrumento para que sinalizem reputação, influenciando as percepções dos usuários quanto à legitimidade de suas operações (Rosa et al., 2011). Aliado a isso, estudos como o de Rover et al. (2008) apontam potencial relação entre o investimento em divulgação de informações e a presença de maior rentabilidade nas empresas.

Assim, tendo em vista o potencial efeito de legitimação sobre a rentabilidade, surgiu a seguinte questão problema: qual a relação existente entre a qualidade da informação ambiental e a rentabilidade das empresas do setor de energia elétrica listadas no ISE? Observa-se que qualidade se fundamenta no nível de acurácia definido com base no padrão GRI.

De modo geral, o estudo objetivou verificar a relação existente entre a qualidade da informação ambiental e a rentabilidade de empresas do setor de energia elétrica pertencentes ao B3 listadas no ISE.

A maioria das pesquisas que discutem sobre ISE enfatizam o valor das ações como elemento para as organizações participarem do grupo de empresas socioambientais (Cavalcante et al., 2007; Rezende, 2007; Machado et al., 2009; Beato et al., 2009; Sato et al., 2010; Gomes \& Tortato, 2011), e poucas são as que atualmente focam suas análises fundamentalistas como, por exemplo, rentabilidade (Silva et al., 2015).

A justificativa para a realização deste estudo baseou-se no aumento da demanda por informações sobre a atuação de empresas que têm como propósito direto o trabalho com recursos naturais e meio ambiente por seus usuários. Nesse sentido, Potrich et al. (2017) 
destacam que o estudo de empresas classificadas como potencialmente poluidoras se acentua porque não há consenso na literatura sobre quais os fatores supervenientes e intervenientes que influenciam de forma efetiva a divulgação de informações ambientais.

Do ponto de vista teórico, a pesquisa discutiu conjuntamente as teorias da sinalização e da legitimação dentro do mercado de capitais das empresas que operam no ISE, a considerar que a primeira teoria pressupõe que ao emitir mais informações para o mercado, em especial de natureza ambiental, gera mais legitimidade para a empresa. Havendo dessa credibilidade, atrairá mais investidores, e o que se espera é que melhore o desempenho econômico. Sob o enfoque empírico, visou-se verificar os potenciais efeitos das teorias da sinalização e legitimação sobre a rentabilidade das empresas do setor de energia elétrica listadas no ISE.

\section{REFERENCIAL TEÓRICO}

Esta seção aborda o referencial teórico e a revisão de literatura, que está disposta em três seções secundárias: a primeira trata acerca das Teorias da Sinalização e Legitimidade; a segunda aborda o padrão de evidenciação ambiental GRI; e a terceira elenca estudos anteriores correlatos à abordagem proposta na pesquisa em foco.

\subsection{TEORIAS DA SINALIZAÇÃO E LEGITIMIDADE}

Elaborada pelo economista Andrew Michael Spence (1973), a Teoria da Sinalização é aplicada para esclarecer o comportamento dos mercados a partir dos sinais emitidos. Esses sinais são definidos pelo autor como atividades ou mecanismos que acontecem de modo planejado ou ocasional e podem alterar crenças e transmitir dados para outros indivíduos, sendo uma fonte de informação confiável para os usuários. O autor enfatiza, ainda, que os sinais emitidos podem ser positivos, negativos ou neutros aos outros agentes do mercado. Os primeiros são interpretados a favorecer quem emite a informação, e os segundos desfavorecem o emissor do sinal (Spence, 1973).

Em seu primeiro livro, o autor citado abordou a ocorrência da sinalização no mercado de trabalho, utilizando como exemplo a existência de assimetria de informações entre - empregador e a pessoa que está sendo contratada ou admitida. $O$ empregador quer contratar o candidato, mas não tem conhecimento da capacidade laborativa desse possível empregado. A ele caberá decidir se deve ou não o contratar, e como as habilidades deste não são conhecidas antecipadamente, tais decisões são incertas. 
Ao admitir, o empregador verificará os atributos que caracterizam a imagem do empregado, podendo eles ser fixos ou variáveis, como o grau de educação ou ensino. $O$ autor denomina como índices os atributos invariáveis, e como sinais, os atributos variáveis. Os sinais são, portanto, meios de discriminação que são possíveis de alterar crenças e repassar informações aos outros indivíduos, aprimorando, assim, a qualidade dos comunicados e facilitando a compreensão das pessoas.

As empresas estão disponibilizando de forma mais expressiva aos atuais e potenciais investidores informações relevantes que exercem papel primordial para definir e executar estratégias para a tomada de decisão, sendo um meio de avaliação de desempenho (Fidelis \& Cândido, 2006). Essas informações são denominadas "sinais", segundo Spence (1973). Desse modo, a divulgação de índices contábeis pode ser considerada uma sinalização (Klann \& Beuren, 2011), cujos indicadores estão relacionados a particularidades da entidade. Segundo Antunes e Procianoy (2003), a confiabilidade das mensagens anunciadas é diretamente proporcional à exequibilidade de as empresas cumprirem com o que é transmitido para a sociedade.

A sinalização feita pelo agente emissor nem sempre exerce o papel desejado pelo transmissor da informação. Ao emiti-la o agente espera por uma reação positiva ou negativa do principal. Todavia, a interpretação do receptor pode ser diferente da definida pelo intermediador. Exemplificando, pode-se destacar uma divulgação no campo ambiental realizada por uma empresa que, ao transmitir a informação de danos ao meio ambiente, objetiva lançar transparência aos seus stakeholders. Contudo, há a possibilidade de a mensagem ser interpretada de forma distinta do que a esperada, ou seja, demonstrar que essa empresa causa danos ao meio ambiente, acarretando possível decisão de não investimento (Silva et al., 2017).

A Teoria da Legitimidade vem sendo bastante utilizada nas pesquisas para explicar as motivações que levam as empresas à divulgação ambiental (Cormier \& Magnan, 2015). Conforme os autores, o disclosure ambiental é economicamente relevante para o mercado financeiro e afeta-o de forma direta ou indireta. Diante disso, os stakeholders se favorecem de maior transparência ao fazerem previsões, e as organizações reforçam sua legitimidade perante a sociedade.

A decisão do administrador de divulgar informações ambientais deve levar em conta tanto as necessidades de informação do mercado financeiro quanto da sociedade, intentando equilibrá-las a ambos os interesses. Havendo o equilíbrio, os investidores terão ferramentas para a tomada de decisão e a sociedade terá uma forma de verificar a responsabilidade socioambiental das empresas (Cormier \& Magnan, 2015).

Dias et al. (2015) definem como Teoria da Legitimidade um recurso teórico que tem como finalidade dar respaldo e ratificar as informações de responsabilidade socioambiental 
recebido pelas organizações. Os stakeholders esperam que as organizações publiquem quais os motivos de um evento ambiental, comprovando a importância de conservar e restaurar a legitimidade por meio da divulgação (Elijido-Ten et al., 2010). Porém, há entidades que dispõem apenas de um envolvimento ambiental representativo em seus relatórios de sustentabilidade, configurando que os stakeholders não provocam mudanças no conteúdo de divulgação ambiental (Rodrigues, 2014).

Percebe-se que a divulgação ambiental é praticada por muitas organizações de forma estrategista (Spence et al., 2010). Estudos empíricos, como o relatado por Rodrigues (2014), comprovaram que as organizações gerenciam as percepções do público, dando ênfase a informações mais positivas e negligenciando as negativas. Demonstraram, ainda, que a legitimidade das organizações está voltada para garantir a continuidade das empresas, e não para procedimentos e comportamentos legítimos em face da sociedade e do meio ambiente. Frente a isso, as pesquisas passaram a investigar a relação e o papel dos stakeholders no processo de divulgação ambiental (Cormier \& Magnan, 2015; Elijido-Tem et al., 2010; Rodrigues).

\subsection{O PADRÃO DE EVIDENCIAÇÃO AMBIENTAL GRI}

A evidenciação ambiental pode ser classificada como um conjunto de recursos aplicado por diversas entidades para mostrar aos stakeholders práticas relativas à questão do meio ambiente e, consequentemente, servir de ferramenta para a tomada de decisões aos interessados nessas informações (Rosa et al., 2014). Compreende dimensões sociais e econômicas e não está associada somente a questões como, por exemplo, a quantidade excessiva de emissão de gases altamente poluentes ao meio ambiente que afetam e prejudicam a saúde dos indivíduos. Também engloba as multas que resultam uma imagem negativa para a empresa, o que poderá a ela ocasionar sérias implicações econômicas (Buhr $\&$ Freedman, 2001).

A divulgação ambiental pode ser elaborada de forma obrigatória, por exigência de leis e regulamentos, ou voluntária, quando as empresas evidenciam de forma espontânea com base em diretrizes e orientações (Nossa, 2002). A forma voluntária de evidenciação, conforme definido por Dantas et al. (2005), é um procedimento autoindutivo de divulgação no qual se percebe quando as atividades entre as organizações e os acionistas pressionam as empresas por meio de incentivos para que venham a publicar as informações.

No Brasil, mesmo não havendo uma lei ou norma específica que obrigue as entidades a divulgarem informações ambientais, muitas o fazem de forma voluntária. Atualmente, entre as iniciativas implantadas de procedimentos para a composição de relatório socioambiental e balanço social, destaca-se o Global Reporting Initiative (GRI). O GRI é um padrão operado 
de forma expressiva no mundo que fornece materialidade e comparabilidade aos relatórios de sustentabilidade e se sobressai ao apresentar referenciais para a produção e melhoria dos relatos (Castilho \& Vasconcelos, 2016).

O GRI é uma organização internacional sem fins lucrativos cuja formação se sucedeu no final da década 1990, mediante ação entre o Programa das Nações Unidas para o Meio Ambiente (PNUMA) e a Coalizition for Environmentally Responsible (CERES). Tem como finalidade ajudar no aperfeiçoamento da qualidade dos relatórios de sustentabilidade emitidos pelas organizações e estimular a adoção voluntária de indicadores com maior rigor, qualidade e aplicação global para se tornar uma prática mais harmônica internacionalmente.

A Organização recomenda que os indicadores sejam divulgados de modo geral ou específico, refletindo a postura de responsabilidade social e ambiental da entidade. Os relatórios requerem a criação com base nos princípios da transparência, relevância, facilidade de compreensão, abrangência, verificabilidade, neutralidade, exatidão, objetividade, dentre outros (Global Reporting Initiative [GRI], 2006).

O Conselho Empresarial Brasileiro para o Desenvolvimento Sustentável (CEBDS, 2017) define o GRI como uma organização internacional e independente que assiste às empresas e outras instituições a assimilar e transmitir o impacto dos negócios em questões críticas relacionadas à sustentabilidade. As diretrizes para o relato de sustentabilidade do padrão GRI oferecem princípios, conteúdos e um manual de implementação para que distintas organizações consigam compor seus relatórios. Elas são constituídas em duas partes: Princípios para Relato e Conteúdos Padrão, que compreendem concepções, conteúdos e critérios a serem utilizados para a elaboração do relatório, e Manual de Implementação. Essas concepções são primordiais para garantir a transparência no processo de relato de sustentabilidade (GRI, 2013).

Segundo Lucena e Travassos (2013), o relatório apresentado pelo GRI é direcionado para proporcionar novos conceitos e práticas que impulsionem o surgimento de novas lideranças e estimulem os administradores para que haja transição para o novo modelo de desenvolvimento da empresa. Os relatórios de sustentabilidades baseados nos padrões GRI devem medir, divulgar e prestar contas às partes interessadas sobre o desempenho das empresas para alcançar o objetivo de um desenvolvimento sustentável.

As empresas devem evidenciar suas ações aos usuários da informação com transparência em prol do benefício de todos. Assim, caberá ao profissional contábil disponibilizar aos acionistas e futuros investidores informações além daquelas obrigatórias, adaptando-se à nova realidade do mercado. Não obstante, essas informações evidenciadas deverão ser apresentadas de maneira acurada, atendendo às expectativas das partes interessadas (Ben, 2005). 


\subsection{ESTUDOS ANTERIORES}

A produção científica em contabilidade ambiental referente à evidenciação e qualidade das informações tem chamado acentuadamente a atenção de pesquisadores brasileiros nos últimos anos, todavia ainda são poucos os estudos que buscam analisar o desempenho econômico sob a perspectiva da evidenciação ambiental. A Tabela 1 apresenta alguns trabalhos relacionados com o tema qualidade da informação ambiental sobre a rentabilidade.

Tabela 1

Relação de estudos realizados quanto à qualidade da informação ambiental sobre a rentabilidade.

\begin{tabular}{cl}
\hline Autores & \multicolumn{1}{c}{ Principais aspectos } \\
\hline \multirow{2}{*}{ Farias (2009) } & $\begin{array}{l}\text { Investigar a inter-relação entre a divulgação ambiental, o desempenho ambiental e o } \\
\text { desempenho econômico de empresas brasileiras de capital aberto. Os resultados do modelo } \\
\text { sugerem que não há mutualidade significante entre as variáveis, conforme as características } \\
\text { da amostra e dos indicadores utilizados. Observou-se que a divulgação ambiental é in- } \\
\text { fluenciada pelo desempenho ambiental, que o desempenho econômico afeta o desempenho } \\
\text { ambiental, mas que a divulgação ambiental não é afetada pelo desempenho econômico. }\end{array}$ \\
\hline \multirow{2}{*}{$\begin{array}{l}\text { Sueyoshi e } \\
\text { Goto (2009) }\end{array}$} & $\begin{array}{l}\text { Investigar se os investimentos e despesas com o meio ambiente poderiam melhorar o desem- } \\
\text { penho financeiro de empresas de energia elétrica dos EUA sob a Lei do Ar limpo, instituída } \\
\text { em 1990. Os resultados demonstraram que não é possível encontrar influência positiva do } \\
\text { investimento ambiental no desempenho financeiro medido pelo ROA. }\end{array}$ \\
\hline
\end{tabular}

Estudar a relação entre o nível de evidenciação ambiental e o desempenho econômico das

Beuren et al. empresas de capital aberto classificadas no Guia Você S/A. Os resultados indicaram que (2013) nem todas as empresas que apresentaram nível significativo de evidenciação ambiental obtiveram satisfatório desempenho econômico.

Fasolin et al.

Verificar a relação entre o índice de sustentabilidade e os indicadores econômico-financeiros das empresas de energia listadas na BM\&FBovespa. Os resultados apontaram que os indicadores econômico-financeiros de tamanho, rentabilidade e endividamento das empresas geradoras e distribuidoras de energia elétrica brasileiras não influenciam o nível de evidenciação das práticas de sustentabilidade dessas companhias.

Analisar a relação entre o disclosure socioambiental, as práticas de governança corporativa e o desempenho das companhias listadas na BM\&FBovespa à luz da Teoria da Sinalização. Os resultados mostraram que a alta adoção de práticas de governança corporativa está associada a um baixo disclosure socioambiental, revelando contradição com o princípio da

Santana et al. transparência, pilar da governança. A análise dos dados sinalizou, ainda, que o disclosure (2015) socioambiental impacta positivamente e temporalmente no desempenho empresarial, considerando-se a variável valor de mercado, e que as práticas de governança corporativa não influenciam o desempenho das empresas da amostra. Conclui-se que somente o disclosure socioambiental apontou o desempenho empresarial, à medida que quanto maior o disclosure maior o desempenho.

Analisar seis empresas no ramo de eletrodomésticos listadas na BOVESPA com o intuito de identificar se elas trabalham a evidenciação ambiental e se esse fator está ligado à sua

Figueiredo et rentabilidade. Como resultado, entendeu-se que entre as seis empresas pesquisadas não al. (2017) há relações significativas entre a evidenciação ambiental e sua rentabilidade, porquanto algumas que não publicaram dados ambientais tiveram rendimentos significativos. Conclui-se que não há necessidade de que as empresas divulguem informações mais precisas sobre o meio ambiente, visto que isso não influiu na sua rentabilidade. 


\begin{tabular}{|c|c|}
\hline Autores & Principais aspectos \\
\hline $\begin{array}{l}\text { Janiszewski et } \\
\text { al. (2017) }\end{array}$ & $\begin{array}{l}\text { Identificar a presença de mecanismos de sinalização no mercado brasileiro por meio de } \\
\text { divulgação de informaçães nos demonstrativos financeiros anuais. A pesquisa encontrou } \\
\text { forte relação dos Indicadores de Divulgação Voluntária com a variação da Rentabilidade } \\
\text { e do Tamanho das empresas em contraste. No que se refere aos níveis de risco, não houve } \\
\text { associação significativa. O estudo provou que empresas tendem a sinalizar, mediante seus } \\
\text { indicadores de performance voluntários, quando ocorre queda no desempenho. }\end{array}$ \\
\hline $\begin{array}{l}\text { Peixoto et al } \\
\text { (2017) }\end{array}$ & $\begin{array}{l}\text { Analisar a relação entre a evidenciação de gastos ambientais refletidos pelo Índice de Di- } \\
\text { vulgação de Gastos Ambientais (IDGA) e o desempenho econômico-financeiro das empresas } \\
\text { de capital aberto potencialmente poluidoras do Brasil. Os resultados destacaram que o } \\
\text { nível da evidenciação ambiental pode influenciar o desempenho econômico-financeiro nas } \\
\text { empresas de capital aberto com alto teor de poluição, assim como a evidenciação de gastos } \\
\text { ambientais também pode ser explicada por organizações que ingressam aos respectivos } \\
\text { índices, destacando que a Teoria da Legitimidade pode ser uma motivadora das entidades } \\
\text { para garantir que sua atividade seja autêntica perante a sociedade. }\end{array}$ \\
\hline $\begin{array}{l}\text { Dutra e Pa- } \\
\text { rente (2018) }\end{array}$ & $\begin{array}{l}\text { Investigar a influência do desempenho ambiental em relação ao desempenho econômico } \\
\text { das empresas listadas na BMF\&Bovespa. Apesar de haver limitações, o estudo apresentou } \\
\text { informações gerenciais relevantes de que empresas com estratégias voltadas para investi- } \\
\text { mentos ambientais representativos não garantem resultados econômicos superiores no curto } \\
\text { prazo, confirmados pelos testes estatísticos de correlação e regressão linear, não indicando } \\
\text { indícios de associação entre o desempenho ambiental e o econômico. }\end{array}$ \\
\hline
\end{tabular}

A partir da análise da Tabela 1 verifica-se não haver consenso sobre a temática ora destacada, sendo necessário dar continuidade ao aprofundamento do conteúdo. Alguns estudos investigaram a relação entre o desempenho da divulgação socioambiental e o desempenho financeiro das organizações em diferentes cenários e períodos, tais como Farias (2009), Sueyoshi e Goto (2009), Beuren et al. (2013), Fasolin et al. (2014), Figueiredo et al. (2017) e Dutra e Parente (2018), que evidenciaram a inexistência de relação a tais desempenhos. Em contrapartida, Santana et al. (2015), Janiszewski et al. (2017) e Peixoto et al. (2017) retrataram a relação positiva dos indicadores de divulgação ambiental com os resultados econômicos das empresas analisadas. Dessa forma, o assunto fornece um hiato a ser explorado.

Tendo como principal aporte teórico a Teoria da Sinalização, algumas investigações foram desenvolvidas a fim de analisar os impactos que os sinais transmitidos pelas empresas podem causar. Assim, considerando as referências teóricas e os estudos empíricos supracitados espera-se que esta pesquisa venha a contribuir para ampliar as discussões acerca da qualidade da informação ambiental sobre a rentabilidade. O tópico a seguir apresenta os aspectos metodológicos que a tornaram possível.

\section{PROCEDIMENTOS METODOLÓGICOS}

Este estudo objetiva verificar a relação existente entre a qualidade da informação ambiental e a rentabilidade de empresas do setor de energia elétrica pertencentes à B3 listadas no ISE. A escolha desse segmento é embasada por ser um campo que apresenta 
alto impacto negativo ao meio ambiente e significativa influência econômica para o Brasil, conforme destacado por Furtado et al. (2019). Para tanto, realizou-se uma pesquisa de natureza descritiva por meio de procedimentos documentais, que se realizou por meio dos métodos qualitativo e quantitativo.

A amostra do estudo consistiu em empresas brasileiras do setor de energia elétrica de capital aberto listadas na B3 que integram carteira do ISE e utilizam as diretrizes do GRI 3.1 ou 4. A fim de alcançar esse resultado foi necessário recorrer aos sites da B3, do GRI e do ISE para identificar as empresas que se enquadravam na amostra do estudo, e para a análise de conteúdo sucedeu-se a busca por meio eletrônico, no próprio site das empresas.

Para o cumprimento dos objetivos tornou-se essencial a busca e análise de demonstrativos econômicos e financeiros obrigatórios da empresa e dos relatórios de sustentabilidade que compõem a amostra. Os recursos utilizados como instrumento de coleta de dados foram: Demonstrações do Resultado do Exercício (DRE), Demonstração do Valor Adicionado (DVA), Balanço Patrimonial (BP), Notas Explicativas (N.E) e Relatório de Sustentabilidade (RS).

Inicialmente foram escolhidas empresas do setor de energia compreendido no período de 2014 a 2017, totalizando 60 instituições. Destas, foram selecionadas aquelas que pertenciam ao ISE, que adotaram o padrão GRI 3.1, GRI 4.0 ou GRI Standards e tinham suas DFPs e os relatórios de sustentabilidade disponíveis para consulta, e realizou-se a posterior comparabilidade do nível de qualidade da divulgação de informações ambientais.

A pesquisa e a coleta inicial dos relatórios, ocorridas em outubro de 2018, resultaram em 10 empresas:

a) Aes Tiete Energia;

b) Cemig Distribuição;

c) Eletrobrás;

d) Copel;

e) CPFL Engenharia;

f) CPFL Energias Renováveis;

g) Edp Energias do Brasil;

h) Eletropaulo;

i) Engie Brasil Energia;

j) Light. 
O padrão adotado para a divulgação de informações ambientais (GRI) serviu de critério para definição da amostra. Para a análise utilizaram-se somente os indicadores de aspectos econômicos, ou seja, os indicadores quantitativos estabelecidos pelas diretrizes do GRI 3.1, GRI 4.0 e GRI Standards.

No GRI 4.0, os indicadores econômicos são formados por quatro aspectos - Desempenho Econômico (EC), Presença no Mercado, Impactos Econômicos Indiretos e Práticas de Compra - diferentemente do GRI 3.1, que é constituído de três aspectos - Desempenho Econômico, Presença no Mercado e Impactos Econômicos Indiretos. Para um entendimento mais preciso dos indicadores ECl ao EC9, o GRI disponibiliza no documento Princípios para Relato e Conteúdos Padrão das Diretrizes G4 e Environment Performance Indicators (IP), que contêm informações detalhadas para cada indicador.

No ano de 2016, ocorreu uma transição do GRI 4.0 para o GRI Standards, compreendido de um conjunto de normas globais, porém somente em 2018 essa transição foi implementada.

A análise de conteúdo foi realizada por meio da decomposição dos indicadores $\mathrm{ECl}$ a EC9, que resultou em subindicadores (SI), conforme detalhado na Tabela 2. Para a averiguação de acurácia nos relatórios de sustentabilidade empregaram-se todos os subindicadores do tipo quantitativo monetário. A acurácia foi definida por meio do desenvolvimento de três afirmações, construídas com base nos testes de autodiagnóstico, recomendados pelo GRI (2011): (i) a informação divulgada no RS é encontrada nas demonstrações financeiras obrigatórias divulgadas; (ii) as informações encontradas nas demonstrações obrigatórias são suficientes para reproduzir ou explicar a informação divulgada no RS; (iii) os valores divulgados no RS não apresentam variação significativa em relação aos valores divulgados nas demonstrações obrigatórias. Caso os três requisitos sejam simultaneamente atendidos, então se classifica acurácia (A).

Quanto às informações, foram denominadas nas seguintes categorias: Acurácia ( $A$ ), Não Acurácia (NA) - por meio da análise temática -, Não Evidenciado (NE) - nos casos que inexistirem informações - e Não disponível (ND) - quando a empresa tem a informação, mas não a divulga nos relatórios por acreditar ser irrelevante para o usuário da informação. 


\section{Tabela 2}

Decomposição dos Indicadores em Subindicadores (SI).

\begin{tabular}{|c|c|c|c|}
\hline \multicolumn{4}{|c|}{ PERSPECTIVA ECONÔMICA } \\
\hline Indicador & Subindicadores (SI) & Tipo & Unidade \\
\hline \multicolumn{4}{|l|}{ Aspecto: Desempenho Econômico } \\
\hline $\begin{array}{l}\text { ECl - Valor econômico direto gerado } \\
\text { e distribuído, incluindo receitas, custos } \\
\text { operacionais, remuneração de empregados, } \\
\text { doações e outros investimentos na comu- } \\
\text { nidade, lucros acumulados e pagamentos } \\
\text { para provedores de capital e governos. }\end{array}$ & $\begin{array}{l}\text { EC1.1 Receitas. } \\
\text { EC1.2 Custos Operacionais. } \\
\text { EC1.3 Salários e Benefícios de Emprega- } \\
\text { dos. } \\
\text { EC1.4 Pagamentos para Provedores de } \\
\text { Capital. } \\
\text { EC1.5 Pagamentos ao Governo. } \\
\text { ECl.6 Investimentos na Comunidade. } \\
\text { EC1.7 Valor Econômico Acumulado. }\end{array}$ & $\begin{array}{l}\text { Quant. } \\
\text { Quant. } \\
\text { Quant. } \\
\text { Quant. } \\
\text { Quant. } \\
\text { Quant. } \\
\text { Quant. }\end{array}$ & $\begin{array}{l}\mathrm{R} \$ \text { milhões } \\
\mathrm{R} \$ \text { milhões } \\
\mathrm{R} \$ \text { milhões } \\
\mathrm{R} \$ \text { milhões } \\
\mathrm{R} \$ \text { milhões } \\
\mathrm{R} \$ \text { milhões } \\
\mathrm{R} \$ \text { milhões }\end{array}$ \\
\hline
\end{tabular}

EC2 - Implicações financeiras e outros riscos e oportunidades para as atividades da organização em razão de mudanças EC2.4 Impactos financeiros de riscos e oportunidades.

Quant. R\$ milhões climáticas.

EC3 - Cobertura das obrigações do plano de pensão de benefício definido que a organização oferece.
EC3.1 Cobertura pela empresa das obrigações do Plano de Benefício Definido. EC3.2 Valor do ativo do Fundo alocado para cobertura do passivo de aposentadorias.
EC4 - Ajuda financeira significativa recebida do governo.

EC4.1 Incentivos Fiscais.

Quant. R\$ milhões

Quant. R\$ milhões

Quant. R\$ milhões

Aspecto: Impactos Econômicos Indiretos

EC8 - Desenvolvimento e impacto de investimentos em infraestrutura e serviços oferecidos, principalmente para benefício público, por meio de engajamento comerEC8.1 Investimentos ou custos em infraestrutura ou serviços para a comunidade ou economias locais.

Quant

R\$ Milhões

Nota. Adaptada de "Qualidade da divulgação socioambiental: Um estudo sobre a acurácia das informações contábeis nos relatórios de sustentabilidade", de S. Garcia, Y.C. Cintra, M. Souza Ribeiro, e B.R.S. Dibbern, 2015, Revista Catarinense da Ciência Contábil, 18, p. 2807.

Para chegar a uma quantificação da divulgação dos relatórios de sustentabilidade empregou-se a fórmula do Índice de acurácia elaborada por Garcia et al. (2015), exposta na Tabela 3. Esse índice é a proporção entre o total da quantidade de respostas que apresentaram acurácia $\left(T_{A C}\right)$ pelo Total de Questões de Acurácia $\left(T_{A C}\right)$, subtraindo o Total de Questões Não aplicáveis $\left(\mathrm{TQ}_{\mathrm{Nap}}\right)$ e o Total de Questões Não Disponíveis $\left(\mathrm{TQ}_{\mathrm{ND}}\right)$. Assim, conforme considerado no estudo de Garcia et al. (2015), o termo Não Disponíveis (ND) diz respeito a quando a empresa tem a informação, mas esta não está disponível, e justifica o motivo da não divulgação, e Não aplicáveis (Nap) concerne a quando a informação do "subindicador" não se aplica ao segmento da empresa. 
Tabela 3

Índice de acurácia

\begin{tabular}{ll}
\hline Índice de acurácia & Escala intervalar \\
\hline$I A C=\frac{T_{A C}}{\left(T Q_{A C}-T Q_{N a p}-T Q_{N D}\right)}$ & IAC $\geq 0,6:$ Alto índice de acurácia. \\
& $0,4 \leq \mathrm{IAC}<0,6:$ Médio índice de acurácia. \\
& $\mathrm{IAC}<0,4:$ Baixo índice de acurácia. \\
\hline
\end{tabular}

Nota. $T_{A C}$ : Total de questões de acurácia respondidas afirmativamente; $T Q_{A C}$ : Total de questões de acurácia; $T Q_{N a p}$ : Total de questões não aplicáveis; $T Q_{N D}$ : Total de questões não disponíveis. Adaptada de "Qualidade da divulgação socioambiental: Um estudo sobre a acurácia das informações contábeis nos relatórios de sustentabilidade", de S. Garcia, Y.C. Cintra, M. Souza Ribeiro, e B.R.S. Dibbern, 2015, Revista Catarinense da Ciência Contábil, 18, p. 2807.

Por meio do resultado obtido do índice de acurácia utilizou-se a Escala Intervalar, que indica o nível em que se enquadra cada empresa analisada. As empresas foram classificadas de acordo com o seu resultado do IAC em uma das três categorias: alto, médio ou baixo índice de acurácia.

Com o propósito de obter os indicadores de qualidade recorreu-se ao site da B3 e das organizações objeto de estudo, bem como os indicadores de rentabilidade previamente calculados e disponibilizados pela base de dados do Economática. Ao se obter o índice, que revelou a qualidade da informação ambiental, realizou-se uma comparação com os indicadores de desempenho de rentabilidade por meio de estimação de Regressão Quantílica (RQ) obtida com o auxílio do pacote quantreg (Koenker, 2018) do software estatístico R (R Core Team, 2020).

Tarr (2012) apresenta que a técnica é capaz de contornar erros com relação à presença de valores nas caudas das distribuições, assim como ocorre de forma comum e natural com os dados econômicos e financeiros. Ohlson e $\mathrm{Kim}$ (2015) assentam que a regressão quantílica é capaz de realizar estimações robustas com dados financeiros e contábeis, visto que, na maioria das vezes, apresentam-se heterocedásticos. Neste estudo, as regressões foram realizadas para o quantil 0,50 .

As regressões quantílicas foram estimadas com o erro-padrão via bootstrap, adotado nas aplicações de regressão quantílica por apresentar bom desempenho em pequenas amostras e matriz de covariância adaptável às diversas formas de heterogeneidade (Koenker, 2005).

À vista disso, com o intuito de verificar a relação entre a qualidade da informação ambiental e a rentabilidade das empresas do setor de energia elétrica listadas no ISE, foram estimados oito modelos para cada organização, tendo como base a regressão quantílica simples. $O$ índice de acurácia foi considerado como variável independente, e os índices de rentabilidade foram conjecturados como variáveis dependentes. Os modelos empregados para análise de regressão são apresentados pelas equações (1) a (7) a seguir: 


$$
\begin{aligned}
& \operatorname{EBITDA}_{i=} \beta_{0}+\beta_{1} \cdot I A C+\varepsilon_{i} \\
& \operatorname{LAIR}_{i=} \beta_{0}+\beta_{1} \cdot I A C+\varepsilon_{i} \\
& \operatorname{MrgBru}_{i=} \beta_{0}+\beta_{1} \cdot I A C+\varepsilon_{i} \\
& \operatorname{MrgEBIT}_{i=} \beta_{0}+\beta_{1} \cdot I A C+\varepsilon_{i} \\
& \operatorname{MrgEBITDA}_{i=} \beta_{0}+\beta_{1} \cdot I A C+\varepsilon_{i} \\
& \operatorname{RentAt}_{i=} \beta_{0}+\beta_{1} \cdot I A C+\varepsilon_{i} \\
& \operatorname{ROIC}_{i=} \beta_{0}+\beta_{1} \cdot I A C+\varepsilon_{i}
\end{aligned}
$$

Em que IAC é o índice de acurácia; EBITDA representa Lucros antes de juros, impostos, depreciação e amortização; LAIR concerne ao Lucro Antes do IR/CS; MrgBru diz respeito à margem bruta; MrgEBIT é a margem EBIT (Lucro antes dos Juros e Tributos); MrgEbtida é a margem Ebitda (Lucro antes dos Juros, Impostos, Depreciação e Amortização); RentAt caracteriza a rentabilidade do ativo; ROIC é o retorno sobre o capital investido; $\beta_{0}$ é a constante e $\beta_{1}$ o coeficiente estimado do IAC, que constituem os parâmetros desconhecidos do modelo; e $\varepsilon_{\mathrm{i}}$ é o erro aleatório.

\section{RESULTADOS E DISCUSSÕES}

O presente estudo objetivou verificar a relação existente entre a qualidade da informação ambiental e a rentabilidade de empresas do setor de energia elétrica pertencentes ao B3 listadas no ISE. Inicialmente, analisou-se o índice de acurácia das empresas.

\section{1 ÍNDICE DE ACURÁCIA}

As empresas foram submetidas a um balanço quanto à acurácia das informações contidas em seus relatórios financeiros e de sustentabilidade e cotejadas com os relatórios financeiros no período de 2014 a 2017. A análise foi desenvolvida por meio de três afirmações construídas com base nos testes de autodiagnóstico relacionadas à AC para cada um dos 12 SI do tipo quantitativo monetário.

$\mathrm{Na}$ Tabela 4 está evidenciado o índice de acurácia (IAC) médio para a maioria das empresas entre os anos de 2014 a 2017. A Cemig, que em 2014 apresentou o maior índice $(0,67)$ entre as empresas no decorrer dos anos, obteve queda, passando o seu IAC para 0,50 , porém permaneceu com o IAC médio. Esse declínio se refere ao SI EC2.4, que trata dos impactos financeiros de riscos e oportunidades - que apresentou não acurácia - apesar 
de ter destacado no RS os métodos utilizados para gerir o risco e as oportunidades, como orienta o IP GRI. Todavia, não mencionou os custos de medidas tomadas para controlar o risco ou as oportunidades, isto é, abordou o tema sem quantificar os custos.

Outra empresa que merece destaque é a Light S/A. No ano de 2014, obteve IAC médio de 0,50 e foi, gradualmente, aumentando esse índice, chegando a 0,83, tendo sido, concomitante com Cemig e Engie, uma das únicas organizações a apresentar níveis de acurácia altos.

\section{Tabela 4}

Resultado da Acurácia das empresas

\begin{tabular}{lccrr}
\multicolumn{1}{c}{ Empresas } & $2014\left(I_{A C)}\right.$ & $2015\left(I_{A C}\right.$ & $2016\left(I_{A C}\right.$ & $2017\left(I_{A C}\right)$ \\
\hline AES Tiete Energia S.A & 0,42 & 0,42 & 0,50 & 0,50 \\
\hline CEMIG Distribuição S/A & 0,67 & 0,50 & 0,58 & 0,50 \\
\hline ELETROBRAS & 0,50 & 0,42 & 0,42 & 0,42 \\
\hline COPEL & 0,42 & 0,42 & 0,42 & 0,50 \\
\hline CPFL Energia & 0,42 & 0,50 & 0,50 & 0,42 \\
\hline CPFL Energias Renováveis & 0,00 & 0,58 & 0,42 & 0,50 \\
\hline EDP Energias do Brasil S.A & 0,58 & 0,42 & 0,58 & 0,42 \\
\hline ELETROPAULO & 0,42 & 0,42 & 0,42 & 0,50 \\
\hline ENGIE BRASIL Energia & 0,58 & 0,67 & 0,67 & 0,58 \\
\hline LIGHT S/A & 0,50 & 0,50 & 0,58 & 0,83 \\
\hline
\end{tabular}

Os resultados revelaram que o grau de acurácia das empresas analisadas no período 2014-2017 é médio, conforme escala intervalar da Tabela 3, corroborando os achados de Garcia et al. (2015).

Para atender ao objetivo delineado nesta pesquisa - investigar a relação existente entre a qualidade da informação ambiental e a rentabilidade das companhias de energia elétrica listadas na B3 -, empregou-se a técnica de Regressão Quantílica, cuja discussão sucede na subseção seguinte.

\subsection{ANÁLISE DE REGRESSÃO QUANTÍLICA}

A seguir são apresentadas as estimações resultantes da regressão quantílica para verificar a relação do índice de acurácia e a rentabilidade das empresas analisadas. Observou-se que, embora haja diferença entre os índices de acurácia evidenciados das empresas da presente pesquisa, a rentabilidade das entidades não está associada ao nível de evidenciação ambiental. 
Tabela 5

Regressão Quantílica AES TIETE ENERGIA S/A (TIET34)

\begin{tabular}{|c|c|c|c|c|c|c|}
\hline \multirow{2}{*}{$\begin{array}{c}\text { Variável depen- } \\
\text { dente }\end{array}$} & \multirow{2}{*}{$\begin{array}{l}\text { Variável expli- } \\
\text { cativa }\end{array}$} & \multicolumn{5}{|c|}{ Quantil } \\
\hline & & 10 & 25 & 50 & 75 & 90 \\
\hline \multirow{2}{*}{ EBITDA } & \multirow{2}{*}{ IAC } & $-5,5789 E+12$ & $-5,5789 E+12$ & $-5,1373 E+12$ & $-6,9695 E+12$ & $-6,9695 E+12$ \\
\hline & & $(0,12)$ & $(0,14)$ & $(0,14)$ & $(0,12)$ & $(0,98)$ \\
\hline \multirow{2}{*}{$L A I R+D F L$} & \multirow{2}{*}{ IAC } & $3,1615 E+10$ & $3,1615 E+11$ & $3,1615 E+11$ & $-6,2297 E+12$ & $-6,2297 E+12$ \\
\hline & & $(0,92)$ & $(0,92)$ & $(0,93)$ & $(0,18)$ & $(0,18)$ \\
\hline \multirow{2}{*}{ Mrg Bru } & \multirow{2}{*}{ IAC } & $3,7200 E+07$ & $3,7200 E+07$ & $3,7200 E+07$ & $-6,0000 E+06$ & $-6,0000 E+06$ \\
\hline & & $(0,23)$ & $(0,24)$ & $(0,24)$ & $(0,80)$ & $(0,80)$ \\
\hline \multirow{2}{*}{ Mrg EBIT } & \multirow{2}{*}{ IAC } & $3,7200 E+07$ & $3,7200 E+07$ & $3,7200 \mathrm{E}+07$ & $-3,6000 E+06$ & $-3,6000 E+06$ \\
\hline & & $(0,23)$ & $(0,23)$ & $(0,24)$ & $(0,87)$ & $(0,87)$ \\
\hline \multirow{2}{*}{ Mrg Ebitda } & \multirow{2}{*}{ IAC } & $4,5600 \mathrm{E}+07$ & $4,5600 E+07$ & $4,5600 \mathrm{E}+07$ & $-2,4000 E+06$ & $-2,4000 E+06$ \\
\hline & & $(0,19)$ & $(0,20)$ & $(0,21)$ & $(0,92)$ & $(0,92)$ \\
\hline \multirow{2}{*}{ RentAt } & \multirow{2}{*}{ IAC } & $3,6000 E+06$ & $3,6000 E+06$ & $3,6000 E+06$ & $-9,6000 E+06$ & $-9,6000 E+06$ \\
\hline & & $(0,72)$ & $(0,74)$ & $(0,73)$ & $(0,40)$ & $(0,42)$ \\
\hline \multirow{2}{*}{ ROIC } & \multirow{2}{*}{ IAC } & $7,2000 E+06$ & $7,2000 E+06$ & $7,2000 E+06$ & $-1,2000 E+07$ & $-1,2000 E+07$ \\
\hline & & $(0,57)$ & $(0,59)$ & $(0,59)$ & $(0,41)$ & $(0,41)$ \\
\hline
\end{tabular}

Conforme Tabela 6, percebe-se que para todos os índices de rentabilidade analisados há ausência de significância estatística a nível de $5 \%$ (para todos os quantis) em relação ao índice de acurácia, com realce para o caso da Tietê Energia S/A, em que a evidenciação ambiental não foi capaz de explicar variações na rentabilidade da empresa.

\section{Tabela 6}

Regressão Quantílica CEMIG DISTRIBUICAO S/A (CMDT23)

\begin{tabular}{|c|c|c|c|c|c|c|}
\hline \multirow{2}{*}{ Variável dependente } & \multirow{2}{*}{ Variável explicativa } & \multicolumn{5}{|c|}{ Quantil } \\
\hline & & 10 & 25 & 50 & 75 & 90 \\
\hline \multirow{2}{*}{ EBITDA } & \multirow{2}{*}{ IAC } & $-4,78 \mathrm{E}+12$ & $-4,78 \mathrm{E}+12$ & $3,53 E+11$ & $2,21 E+11$ & $2,21 E+11$ \\
\hline & & $(0,57)$ & $(0,54)$ & $(0,56)$ & $(0,71)$ & $(0,69)$ \\
\hline \multirow{2}{*}{$L A I R+D F L$} & \multirow{2}{*}{ IAC } & $-4,34 \mathrm{E}+12$ & $-4,34 \mathrm{E}+12$ & $4,33 E+12$ & $2,31 E+11$ & $2,31 E+11$ \\
\hline & & $(0,62)$ & $(0,62)$ & $(0,51)$ & $(0,71)$ & $(0,72)$ \\
\hline \multirow{2}{*}{ Mrg Bru } & \multirow{2}{*}{ IAC } & $3,60 E+06$ & $3,60 E+06$ & $5,40 E+06$ & $3,00 E+06$ & $3,00 E+06$ \\
\hline & & $(0,28)$ & $(0,29)$ & $(0,15)$ & $(0,35)$ & $(0,32)$ \\
\hline \multirow{2}{*}{ Mrg EBIT } & \multirow{2}{*}{ IAC } & $-3,60 E+06$ & $4,20 E+06$ & $4,20 E+06$ & $2,40 E+06$ & $2,40 E+06$ \\
\hline & & $(0,65)$ & $(0,42)$ & $(0,42)$ & $(0,65)$ & $(0,63)$ \\
\hline \multirow{2}{*}{ Mrg Ebitda } & \multirow{2}{*}{ IAC } & $-3,60 E+06$ & $-3,60 E+06$ & $3,60 E+06$ & $3,00 E+06$ & $3,00 E+06$ \\
\hline & & $(0,61)$ & $(0,59)$ & $(0,48)$ & $(0,55)$ & $(0,54)$ \\
\hline
\end{tabular}




\begin{tabular}{|c|c|c|c|c|c|c|}
\hline \multirow{2}{*}{ Variável dependente } & \multirow{2}{*}{ Variável explicativa } & \multicolumn{5}{|c|}{ Quantil } \\
\hline & & 10 & 25 & 50 & 75 & 90 \\
\hline \multirow{2}{*}{ RentAt } & \multirow{2}{*}{ IAC } & $-1,20 E+06$ & $-1,20 E+06$ & $2,40 E+06$ & $6,00 E+05$ & $6,00 E+05$ \\
\hline & & $(0,75)$ & $(0,74)$ & $(0,39)$ & $(0,84)$ & $(0,85)$ \\
\hline \multirow{2}{*}{ ROIC } & \multirow{2}{*}{ IAC } & $-1,20 E+06$ & $-1,20 E+06$ & $3,00 E+06$ & $1,80 E+06$ & $1,80 E+06$ \\
\hline & & $(0,77)$ & $(0,79)$ & $(0,40)$ & $(0,58)$ & $(0,58)$ \\
\hline
\end{tabular}

A Tabela 6, representada pela CEMIG, revela que a variável explicativa não influenciou os índices de rentabilidade das empresas analisadas, isto é, as variáveis dependentes. Isso significa que o índice de divulgação de informações sociais e ambientais das empresas analisadas não explicou uma possível variabilidade na rentabilidade.

Tabela 7

Regressão Quantílica ELETROBRAS (ELET3)

\begin{tabular}{|c|c|c|c|c|c|c|}
\hline \multirow{2}{*}{$\begin{array}{c}\text { Variável } \\
\text { dependente }\end{array}$} & \multirow{2}{*}{ Variável explicativa } & \multicolumn{5}{|c|}{ Quantil } \\
\hline & & 10 & 25 & 50 & 75 & 90 \\
\hline \multirow{2}{*}{ EBITDA } & \multirow{2}{*}{ IAC } & $1,26 \mathrm{E}+14$ & $1,26 E+14$ & $-8,31 E+13$ & $-2,40 E+14$ & $-2,40 E+14$ \\
\hline & & $(0,37)$ & $(0,36)$ & $(0,53)$ & $(0,17)$ & $(0,17)$ \\
\hline \multirow{2}{*}{$L A I R+D F L$} & \multirow{2}{*}{ IAC } & $1,27 E+14$ & $1,27 E+14$ & $-8,34 E+13$ & $-2,39 E+14$ & $-2,39 E+14$ \\
\hline & & $(0,35)$ & $(0,32)$ & $(0,53)$ & $(0,18)$ & $(0,17)$ \\
\hline \multirow{2}{*}{ Mrg Bru } & \multirow{2}{*}{ IAC } & $-2,40 E+06$ & $-2,40 E+06$ & $-1,56 \mathrm{E}+07$ & $-3,24 \mathrm{E}+07$ & $-3,24 \mathrm{E}+07$ \\
\hline & & $(0,80)$ & $(0,81)$ & $(0,33)$ & $(0,15)$ & $(0,15)$ \\
\hline \multirow{2}{*}{ Mrg EBIT } & \multirow{2}{*}{ IAC } & $3,84 \mathrm{E}+07$ & $3,84 \mathrm{E}+07$ & $-2,28 \mathrm{E}+07$ & $-4,32 \mathrm{E}+07$ & $-4,32 E+07$ \\
\hline & & $(0,28)$ & $(0,30)$ & $(0,51)$ & $(0,23)$ & $(0,19)$ \\
\hline \multirow{2}{*}{ Mrg Ebitda } & \multirow{2}{*}{$\mathrm{IAC}$} & $3,84 \mathrm{E}+07$ & $3,84 \mathrm{E}+07$ & $-2,28 \mathrm{E}+07$ & $-4,08 \mathrm{E}+07$ & $-4,08 E+07$ \\
\hline & & $(0,29)$ & $(0,30)$ & $(0,50)$ & $(0,23)$ & $(0,20)$ \\
\hline \multirow{2}{*}{ RentAt } & \multirow{2}{*}{$\mathrm{IAC}$} & $9,60 E+06$ & $9,60 E+06$ & $-1,20 E+06$ & $-4,80 E+06$ & $-4,80 E+06$ \\
\hline & & $(0,21)$ & $(0,22)$ & $(0,83)$ & $(0,32)$ & $(0,26)$ \\
\hline \multirow{2}{*}{ ROIC } & \multirow{2}{*}{$\mathrm{IAC}$} & $7,20 E+06$ & $7,20 E+06$ & $-3,60 E+06$ & $-1,20 E+07$ & $-1,20 E+07$ \\
\hline & & $(0,32)$ & $(0,30)$ & $(0,60)$ & $(0,20)$ & $(0,19)$ \\
\hline
\end{tabular}

Os resultados da RQ para a empresa Eletrobrás (Tabela 7) indicaram que a divulgação socioambiental não influenciou os indicadores de rentabilidade. Assim, não se encontrou qualquer relação estatisticamente significativa com os indicadores. 


\section{Tabela 8}

Regressão Quantílica COPEL (CPEL15)

\begin{tabular}{|c|c|c|c|c|c|c|}
\hline \multirow{2}{*}{ Variável dependente } & \multirow{2}{*}{$\begin{array}{c}\text { Variável explica- } \\
\text { tiva }\end{array}$} & \multicolumn{5}{|c|}{ Quantil } \\
\hline & & 10 & 25 & 50 & 75 & 90 \\
\hline \multirow{2}{*}{ EBITDA } & \multirow{2}{*}{ IAC } & $6,40 E+11$ & $6,40 E+11$ & $3,45 E+12$ & $1,45 \mathrm{E}+12$ & $1,45 E+12$ \\
\hline & & $(0,14)$ & $(0,15)$ & $(0,27)$ & $(0,48)$ & $(0,46)$ \\
\hline \multirow{2}{*}{$L A I R+D F L$} & \multirow{2}{*}{ IAC } & $5,18 E+11$ & $5,18 E+11$ & $2,79 E+12$ & $1,17 E+12$ & $1,17 E+12$ \\
\hline & & $(0,15)$ & $(0,15)$ & $(0,25)$ & $(0,52)$ & $(0,46)$ \\
\hline \multirow{2}{*}{ Mrg Bru } & \multirow{2}{*}{ IAC } & $4,80 E+06$ & $4,80 E+06$ & $4,80 E+06$ & $2,40 E+06$ & $2,40 E+06$ \\
\hline & & $(0,16)$ & $(0,16)$ & $(0,14)$ & $(0,30)$ & $(0,31)$ \\
\hline \multirow{2}{*}{ Mrg EBIT } & \multirow{2}{*}{ IAC } & $3,60 E+06$ & $3,60 E+06$ & $2,40 E+06$ & $-1,20 E+06$ & $-1,20 E+06$ \\
\hline & & $(0,17)$ & $(0,18)$ & $(0,30)$ & $(0,48)$ & $(0,50)$ \\
\hline \multirow{2}{*}{ Mrg Ebitda } & \multirow{2}{*}{ IAC } & $3,60 E+06$ & $3,60 E+06$ & $2,40 E+06$ & $-1,20 E+06$ & $-1,20 E+06$ \\
\hline & & $(0,17)$ & $(0,17)$ & $(0,31)$ & $(0,52)$ & $(0,52)$ \\
\hline \multirow{2}{*}{ RentAt } & \multirow{2}{*}{ IAC } & $0,00 E+O O$ & $0,00 E+00$ & $-1,20 E+06$ & $-2,40 E+06$ & $-2,40 E+06$ \\
\hline & & $(1,00)$ & $(1,00)$ & $(0,30)$ & $(0,15)$ & $(0,15)$ \\
\hline \multirow{2}{*}{ ROIC } & \multirow{2}{*}{ IAC } & $0,00 E+00$ & $0,00 E+00$ & $0,00 E+00$ & $-1,20 E+06$ & $-1,20 E+06$ \\
\hline & & $(1,00)$ & $(1,00)$ & $(1,00)$ & $(0,17)$ & $(0,16)$ \\
\hline
\end{tabular}

Ao se analisarem os dados apresentados na Tabela 8 verificou-se não haver relação significante entre os desempenhos econômico e ambiental ao nível de $5 \%$, pois os quantis $10,25,50,75$ e 90 não inclinaram para zero, sendo o menor resultado encontrado 0,14 nos quantis 10 referente ao EBITDA e 50 - Margem de lucro.

\section{Tabela 9}

Regressão Quantílica CPFL ENERGIA (CPFE15)

\begin{tabular}{|c|c|c|c|c|c|c|}
\hline \multirow{2}{*}{$\begin{array}{c}\text { Variável } \\
\text { dependente }\end{array}$} & \multirow{2}{*}{$\begin{array}{c}\text { Variável } \\
\text { explicativa }\end{array}$} & \multicolumn{5}{|c|}{ Quantil } \\
\hline & & 10 & 25 & 50 & 75 & 90 \\
\hline \multirow{2}{*}{ EBITDA } & \multirow{2}{*}{ IAC } & $-1,30 E+10$ & $-1,30 E+10$ & $4,39 E+12$ & $-8,86 E+12$ & $-8,86 E+12$ \\
\hline & & $(0,99)$ & $(0,99)$ & $(0,58)$ & $(0,32)$ & $(0,31)$ \\
\hline \multirow{2}{*}{ LAIR+DFL } & \multirow{2}{*}{ IAC } & $-1,57 E+12$ & $-1,57 \mathrm{E}+12$ & $2,81 E+12$ & $-6,00 E+12$ & $-6,00 E+12$ \\
\hline & & $(0,73)$ & $(0,76)$ & $(0,60)$ & $(0,32)$ & $(0,32)$ \\
\hline \multirow{2}{*}{ Mrg Bru } & \multirow{2}{*}{ IAC } & $0,00 E+00$ & $0,00 E+00$ & $4,80 E+06$ & $0,00 E+00$ & $0,00 E+00$ \\
\hline & & $(1,00)$ & $(1,00)$ & $(0,24)$ & $(1,00)$ & $(1,00)$ \\
\hline \multirow{2}{*}{ Mrg EBIT } & \multirow{2}{*}{ IAC } & 0 & 0 & 3.600 .000 & 0 & 0 \\
\hline & & $(1,00)$ & $(1,00)$ & $(0,24)$ & $(1,00)$ & $(1,00)$ \\
\hline \multirow{2}{*}{ Mrg Ebitda } & \multirow{2}{*}{ IAC } & $1,20 E+06$ & $1,20 E+06$ & $1,20 E+06$ & $0,00 E+00$ & $0,00 E+00$ \\
\hline & & $(0,67)$ & $(0,70)$ & $(0,67)$ & $(100000,00)$ & $(100000,00)$ \\
\hline \multirow{2}{*}{ RentAt } & \multirow{2}{*}{ IAC } & $-1,20 E+06$ & $-1,20 E+06$ & $-1,20 E+06$ & $-1,20 E+06$ & $-1,20 E+06$ \\
\hline & & $(0,07)$ & $(0,07)$ & $(0,08)$ & $(0,11)$ & $(0,11)$ \\
\hline \multirow{2}{*}{ ROIC } & \multirow{2}{*}{ IAC } & $0,00 E+00$ & $0,00 E+00$ & $0,00 E+00$ & $-1,20 E+06$ & $-1,20 E+06$ \\
\hline & & $(1,00)$ & $(1,00)$ & $(1,00)$ & $(0,17)$ & $(0,16)$ \\
\hline
\end{tabular}


O índice de acurácia que se considerou como variável explicativa e os índices de rentabilidade estimados como variáveis dependentes, ao serem aplicados ao teste de regressão quantílica na Tabela 9, referente à CPFL ENERGIA, não apresentaram nenhum dado com significância, reiterando os resultados das demais tabelas.

\section{Tabela 10}

Regressão Quantílica CPFL ENERGIAS RENOVAVEIS (ERSAI1)

\begin{tabular}{|c|c|c|c|c|c|c|}
\hline \multirow{2}{*}{$\begin{array}{c}\text { Variável } \\
\text { dependente }\end{array}$} & \multirow{2}{*}{ Variável explicativa } & \multicolumn{5}{|c|}{ Quantil } \\
\hline & & 10 & 25 & 50 & 75 & 90 \\
\hline \multirow{2}{*}{ EBITDA } & \multirow{2}{*}{ IAC } & $5,79 E+10$ & $5,79 E+11$ & $7,91 E+11$ & $1,12 E+12$ & $1,12 \mathrm{E}+12$ \\
\hline & & $(0,57)$ & $(0,63)$ & $(0,59)$ & $(0,51)$ & $(0,49)$ \\
\hline \multirow{2}{*}{$L A I R+D F L$} & \multirow{2}{*}{ IAC } & $3,93 E+10$ & $3,93 E+10$ & $5,01 E+10$ & $7,47 E+10$ & $7,47 \mathrm{E}+11$ \\
\hline & & $(0,61)$ & $(0,48)$ & $(0,56)$ & $(0,45)$ & $(0,57)$ \\
\hline \multirow{2}{*}{ Mrg Bru } & \multirow{2}{*}{ IAC } & $1,54 \mathrm{E}+06$ & $1,54 \mathrm{E}+06$ & $2,00 E+06$ & $2,16 \mathrm{E}+06$ & $2,16 \mathrm{E}+06$ \\
\hline & & $(0,21)$ & $(0,25)$ & $(0,17)$ & $(0,20)$ & $(0,19)$ \\
\hline \multirow{2}{*}{ Mrg EBIT } & \multirow{2}{*}{ IAC } & $1,92 E+06$ & $1,92 E+06$ & $2,06 \mathrm{E}+06$ & $2,40 E+06$ & $2,40 E+06$ \\
\hline & & $(0,14)$ & $(0,18)$ & $(0,17)$ & $(0,22)$ & $(0,20)$ \\
\hline \multirow{2}{*}{ Mrg Ebitda } & \multirow{2}{*}{ IAC } & $1,68 \mathrm{E}+06$ & $1,68 \mathrm{E}+06$ & $1,80 E+06$ & $2,40 E+06$ & $2,40 E+06$ \\
\hline & & $(0,36)$ & $(0,34)$ & $(0,26)$ & $(0,19)$ & $(0,19)$ \\
\hline \multirow{2}{*}{ RentAt } & \multirow{2}{*}{ IAC } & $0,00 E+00$ & $0,00 E+00$ & $1,71 E+05$ & $2,00 E+05$ & $2,00 E+05$ \\
\hline & & $(1,00)$ & $(1,00)$ & $(0,65)$ & $(0,58)$ & $(0,63)$ \\
\hline \multirow{2}{*}{ ROIC } & \multirow{2}{*}{ IAC } & $3,43 E+05$ & $3,43 E+05$ & $4,80 E+05$ & $6,00 E+05$ & $6,00 E+05$ \\
\hline & & $(0,56)$ & $(0,47)$ & $(0,47)$ & $(0,42)$ & $(0,44)$ \\
\hline
\end{tabular}

De acordo com os resultados apresentados na Tabela 10 quanto às variáveis dependentes da CPFL Energias Renováveis, fica evidenciado que a divulgação dos RS não influenciou na rentabilidade apresentada pelas empresas por meio de informações não financeiras, de natureza social e ambiental.

Tabela 11

Regressão Quantílica EDP ENERGIAS DO BRASIL S.A (ENBR24)

\begin{tabular}{|c|c|c|c|c|c|c|}
\hline \multirow{2}{*}{$\begin{array}{c}\text { Variável } \\
\text { dependente }\end{array}$} & \multirow{2}{*}{$\begin{array}{c}\text { Variável } \\
\text { explicativa }\end{array}$} & \multicolumn{5}{|c|}{ Quantil } \\
\hline & & 10 & 25 & 50 & 75 & 90 \\
\hline \multirow{2}{*}{ EBITDA } & \multirow{2}{*}{ IAC } & $-1,95 E+12$ & $-1,95 E+12$ & $-1,95 E+12$ & $-4,24 \mathrm{E}+12$ & $-4,24 \mathrm{E}+12$ \\
\hline & & $(0,49)$ & $(0,46)$ & $(0,47)$ & $(0,22)$ & $(0,21)$ \\
\hline \multirow{2}{*}{$L A I R+D F L$} & \multirow{2}{*}{ IAC } & $-5,35 E+10$ & $-5,35 E+10$ & $-5,35 E+10$ & $-4,73 E+12$ & $-4,73 E+12$ \\
\hline & & $(0,83)$ & $(0,84)$ & $(0,85)$ & $(0,19)$ & $(0,20)$ \\
\hline
\end{tabular}




\begin{tabular}{|c|c|c|c|c|c|c|}
\hline \multirow{2}{*}{$\begin{array}{c}\text { Variável } \\
\text { dependente }\end{array}$} & \multirow{2}{*}{$\begin{array}{c}\text { Variável } \\
\text { explicativa }\end{array}$} & \multicolumn{5}{|c|}{ Quantil } \\
\hline & & 10 & 25 & 50 & 75 & 90 \\
\hline \multirow{2}{*}{ Mrg Bru } & \multirow{2}{*}{ IAC } & $6,00 E+05$ & $6,00 E+05$ & $-6,00 E+05$ & $1,20 E+06$ & $1,20 E+06$ \\
\hline & & $(0,62)$ & $(0,61)$ & $(0,62)$ & $(0,37)$ & $(0,35)$ \\
\hline \multirow{2}{*}{ Mrg EBIT } & \multirow{2}{*}{ IAC } & $2,40 E+06$ & $2,40 E+06$ & $-4,20 E+06$ & $-3,60 E+06$ & $-3,60 E+06$ \\
\hline & & $(0,49)$ & $(0,47)$ & $(0,30)$ & $(0,33)$ & $(0,33)$ \\
\hline \multirow{2}{*}{ Mrg Ebitda } & \multirow{2}{*}{ IAC } & $1,80 E+06$ & $1,80 E+06$ & $-4,80 E+06$ & $-3,60 E+06$ & $-3,60 E+06$ \\
\hline & & $(0,61)$ & $(0,60)$ & $(0,26)$ & $(0,36)$ & $(0,35)$ \\
\hline \multirow{2}{*}{ RentAt } & \multirow{2}{*}{ IAC } & $6,00 E+05$ & $6,00 E+05$ & $-2,40 E+06$ & $-1,20 E+06$ & $-1,20 E+06$ \\
\hline & & $(0,72)$ & $(0,72)$ & $(0,25)$ & $(0,47)$ & $(0,50)$ \\
\hline \multirow{2}{*}{ ROIC } & \multirow{2}{*}{ IAC } & $6,00 E+05$ & $6,00 E+05$ & $-1,80 E+06$ & $-6,00 E+05$ & $-6,00 E+05$ \\
\hline & & $(0,67)$ & $(0,66)$ & $(0,27)$ & $(0,66)$ & $(0,68)$ \\
\hline
\end{tabular}

Por meio dos dados apresentados na Tabela 11, representada pela EDP Energias do Brasil, percebeu-se que os resultados obtidos não foram significantes, assim como a relação entre as oito variáveis foi neutra em relação aos IACs. Dessa forma, o aumento no disclosure socioambiental não sinalizou aumento ou diminuição nos indicadores de rentabilidade.

\section{Tabela 12}

Regressão Quantílica ELETROPAULO (ELPLA3)

\begin{tabular}{|c|c|c|c|c|c|c|}
\hline \multirow{2}{*}{$\begin{array}{c}\text { Variável } \\
\text { dependente }\end{array}$} & \multirow{2}{*}{$\begin{array}{c}\text { Variável } \\
\text { explicativa }\end{array}$} & \multicolumn{5}{|c|}{ Quantil } \\
\hline & & 10 & 25 & 50 & 75 & 90 \\
\hline \multirow{2}{*}{ EBITDA } & \multirow{2}{*}{ IAC } & $7,03 E+12$ & $7,03 E+12$ & $3,93 E+11$ & $1,18 E+12$ & $1,18 E+12$ \\
\hline & & $(0,15)$ & $(0,15)$ & $(0,24)$ & $(0,56)$ & $(0,59)$ \\
\hline \multirow{2}{*}{$L A I R+D F L$} & \multirow{2}{*}{ IAC } & $6,39 E+12$ & $6,39 E+12$ & $3,53 E+12$ & $7,83 E+11$ & $7,83 E+11$ \\
\hline & & $(0,15)$ & $(0,15)$ & $(0,26)$ & $(0,73)$ & $(0,70)$ \\
\hline \multirow{2}{*}{ Mrg Bru } & \multirow{2}{*}{ IAC } & $4,80 E+06$ & $4,80 E+06$ & $2,40 E+06$ & $1,20 E+06$ & $1,20 E+06$ \\
\hline & & $(0,15)$ & $(0,15)$ & $(0,25)$ & $(0,41)$ & $(0,41)$ \\
\hline \multirow{2}{*}{ Mrg EBIT } & \multirow{2}{*}{ IAC } & $4,80 E+06$ & $4,80 E+06$ & $2,40 E+06$ & $1,20 E+06$ & $1,20 E+06$ \\
\hline & & $(0,15)$ & $(0,15)$ & $(0,28)$ & $(0,42)$ & $(0,45)$ \\
\hline \multirow{2}{*}{ Mrg Ebitda } & \multirow{2}{*}{ IAC } & $3,60 E+06$ & $3,60 E+06$ & $2,40 E+06$ & $1,20 E+06$ & $1,20 E+06$ \\
\hline & & $(0,13)$ & $(0,15)$ & $(0,20)$ & $(0,36)$ & $(0,35)$ \\
\hline \multirow{2}{*}{ RentAt } & \multirow{2}{*}{ IAC } & $-6,00 E+06$ & $-6,00 E+06$ & $-7,20 E+06$ & $-8,40 E+06$ & $-8,40 E+06$ \\
\hline & & $(0,19)$ & $(0,20)$ & $(0,17)$ & $(0,15)$ & $(0,15)$ \\
\hline \multirow{2}{*}{ ROIC } & \multirow{2}{*}{ IAC } & 3.600 .000 & 3.600 .000 & 1.200 .000 & 0 & 0 \\
\hline & & $(0,16)$ & $(0,16)$ & $(0,48)$ & $(1,00)$ & $(1,00)$ \\
\hline
\end{tabular}

A partir da Regressão Quantílica Eletropaulo (Tabela 12) quanto ao disclosure socioambiental, verificou-se não haver relação com os indicadores das variáveis dependentes. 
Tabela 13

Regressão Quantílica ENGIE BRASIL ENERGIA (TBLE15)

\begin{tabular}{|c|c|c|c|c|c|c|}
\hline \multirow{2}{*}{$\begin{array}{c}\text { Variável } \\
\text { dependente }\end{array}$} & \multirow{2}{*}{$\begin{array}{c}\text { Variável } \\
\text { explicativa }\end{array}$} & \multicolumn{5}{|c|}{ Quantil } \\
\hline & & 10 & 25 & 50 & 75 & 90 \\
\hline \multirow{2}{*}{ EBITDA } & \multirow{2}{*}{ IAC } & $1,88 \mathrm{E}+12$ & $1,88 \mathrm{E}+12$ & $-5,37 E+12$ & $-4,74 \mathrm{E}+12$ & $-4,74 \mathrm{E}+12$ \\
\hline & & $(0,61)$ & $(0,61)$ & $(0,25)$ & $(0,27)$ & $(0,27)$ \\
\hline \multirow{2}{*}{ LAIR+DFL } & \multirow{2}{*}{ IAC } & $1,42 \mathrm{E}+12$ & $1,42 \mathrm{E}+12$ & $-5,14 E+12$ & $-4,16 E+11$ & $-4,16 E+12$ \\
\hline & & $(0,64)$ & $(0,66)$ & $(0,24)$ & $(0,30)$ & $(0,30)$ \\
\hline \multirow{2}{*}{ Mrg Bru } & \multirow{2}{*}{ IAC } & $3,60 E+06$ & $3,60 E+06$ & $-1,20 E+06$ & $0,00 E+00$ & $0,00 E+00$ \\
\hline & & $(0,24)$ & $(0,25)$ & $(0,64)$ & $(1,00)$ & $(1,00)$ \\
\hline \multirow{2}{*}{ Mrg EBIT } & \multirow{2}{*}{ IAC } & $2,40 E+06$ & $2,40 E+06$ & $-3,60 E+06$ & $-3,60 E+06$ & $-3,60 E+06$ \\
\hline & & $(0,43)$ & $(0,45)$ & $(0,32)$ & $(0,30)$ & $(0,28)$ \\
\hline \multirow{2}{*}{ Mrg Ebitda } & \multirow{2}{*}{ IAC } & $2,40 E+06$ & $2,40 E+06$ & $-3,60 E+06$ & $-2,40 E+06$ & $-2,40 E+06$ \\
\hline & & $(0,47)$ & $(0,46)$ & $(0,31)$ & $(0,45)$ & $(0,46)$ \\
\hline \multirow{2}{*}{ RentAt } & \multirow{2}{*}{ IAC } & $0,00 E+00$ & $0,00 E+00$ & $0,00 E+00$ & $1,20 E+06$ & $1,20 E+06$ \\
\hline & & $(1,00)$ & $(1,00)$ & $(1,00)$ & $(0,18)$ & $(0,17)$ \\
\hline \multirow{2}{*}{ ROIC } & \multirow{2}{*}{ IAC } & 1.200 .000 & 1.200 .000 & 0 & 0 & 0 \\
\hline & & $(0,17)$ & $(0,18)$ & $(1,00)$ & $(1,00)$ & $(1,00)$ \\
\hline
\end{tabular}

Segundo a Tabela 13, nenhuma das variáveis dependentes econômico-financeiras foi considerada estatisticamente significante ao nível de $5 \%$ ( $p$-value $<0,05)$, ou seja, o IAC não influenciou significativamente nos índices de rentabilidade das empresas geradoras e distribuidoras de energia elétrica no Brasil listadas na B3.

\section{Tabela 14}

Regressão Quantílica LIGHT (LIGHC2)

\begin{tabular}{|c|c|c|c|c|c|c|}
\hline \multirow{2}{*}{$\begin{array}{c}\text { Variável depen- } \\
\text { dente }\end{array}$} & \multirow{2}{*}{$\begin{array}{c}\text { Variável explica- } \\
\text { tiva }\end{array}$} & \multicolumn{5}{|c|}{ Quantil } \\
\hline & & 10 & 25 & 50 & 75 & 90 \\
\hline \multirow{2}{*}{ EBITDA } & \multirow{2}{*}{ IAC } & $2,28 \mathrm{E}+11$ & $2,28 E+11$ & $1,91 E+11$ & $4,20 E+11$ & $4,20 E+11$ \\
\hline & & $(0,34)$ & $(0,27)$ & $(0,44)$ & $(0,88)$ & $(0,88)$ \\
\hline \multirow{2}{*}{ LAIR+DFL } & \multirow{2}{*}{ IAC } & $2,17 E+11$ & $2,17 E+11$ & $1,73 E+11$ & $1,14 \mathrm{E}+11$ & $1,14 E+11$ \\
\hline & & $(0,39)$ & $(0,33)$ & $(0,56)$ & $(0,97)$ & $(0,97)$ \\
\hline \multirow{2}{*}{ Mrg Bru } & \multirow{2}{*}{ IAC } & $3,20 E+06$ & $3,20 E+06$ & $2,70 E+06$ & $3,00 E+05$ & $3,00 E+05$ \\
\hline & & $(0,36)$ & $(0,41)$ & $(0,49)$ & $(0,94)$ & $(0,95)$ \\
\hline \multirow{2}{*}{ Mrg EBIT } & \multirow{2}{*}{ IAC } & $2,40 E+06$ & $2,40 E+06$ & $1,80 E+06$ & $-3,00 E+05$ & $-3,00 E+05$ \\
\hline & & $(0,41)$ & $(0,51)$ & $(0,61)$ & $(0,95)$ & $(0,94)$ \\
\hline \multirow{2}{*}{ Mrg Ebitda } & \multirow{2}{*}{ IAC } & $2,00 E+05$ & $2,00 E+06$ & $1,80 E+06$ & $-3,00 E+05$ & $-3,00 E+05$ \\
\hline & & $(0,44)$ & $(0,38)$ & $(0,49)$ & $(0,93)$ & $(0,94)$ \\
\hline
\end{tabular}




\begin{tabular}{|c|c|c|c|c|c|c|}
\hline \multirow{2}{*}{$\begin{array}{l}\text { Variável depen- } \\
\text { dente }\end{array}$} & \multirow{2}{*}{$\begin{array}{c}\text { Variável explica- } \\
\text { tiva }\end{array}$} & \multicolumn{5}{|c|}{ Quantil } \\
\hline & & 10 & 25 & 50 & 75 & 90 \\
\hline \multirow{2}{*}{ RentAt } & \multirow{2}{*}{ IAC } & $1,20 E+06$ & $1,20 E+06$ & $3,00 E+05$ & $-6,00 E+05$ & $-6,00 E+05$ \\
\hline & & $(0,56)$ & $(0,60)$ & $(0,88)$ & $(0,81)$ & $(0,83)$ \\
\hline \multirow{2}{*}{ ROIC } & \multirow{2}{*}{ IAC } & $1,20 E+06$ & $1,20 E+06$ & $1,20 E+06$ & $-3,00 E+05$ & $-3,00 E+05$ \\
\hline & & $(0,57)$ & $(0,47)$ & $(0,59)$ & $(0,90)$ & $(0,90)$ \\
\hline
\end{tabular}

A Light S.A (Tabela 14) foi a única que teve, em 2017, o índice de acurácia considerada alta. Entretanto, mesmo com esse resultado positivo a empresa segue as orientações de forma mais adequada aos parâmetros GRI, não se percebendo significância estatística nos quantis analisados.

De forma geral, concebeu-se que todas as variáveis dependentes apresentadas nas tabelas (5-14) não foram significativas estatisticamente ao nível de 5\%. Dessa forma, para a amostra analisada um maior nível de evidenciação captado pelo índice de acurácia não apresentou relação com os indicadores de rentabilidade, indicando que os investimentos ambientais, mesmo favorecendo a imagem das empresas, não representaram para a amostra escolhida fator de crescimento econômico.

A respeito dos achados, é preciso ponderar que as empresas analisadas simultaneamente estão listadas em outros índices da B3, entre eles IEE - leeletrica (Cemig Distribuição, Eletrobras, Copel, Cpfl Energia, Eletropaulo, Engie Brasil Energia), Ibrx 50 (Cemig Distribuição, Eletrobras), Igc - Igovernanca (Cemig Distribuição, Cpfl Energia, Copel, Cpfl Energia, Eletrobras, Eletropaulo), corroborando os alcançados de Machado et al. (2009), o que pode justificar os resultados.

Salienta-se, ainda, que o retorno econômico-financeiro não é o único meio para uma empresa criar valor ao acionista e aos demais stakeholders. Estudos apontaram que organizações com responsabilidade socioambiental apresentam melhor gestão estratégica e ficam sujeitas a menores níveis de volatilidade (Hoti et al, 2007; Porter \& Van der Linde, 1995) e, consequentemente, menos riscos (Barth et al., 1997; Bansal \& Clelland, 2004). Além disso, os indicadores econômicos das entidades não influenciam nos níveis de evidenciação praticados, apontando indícios de não associação entre o desempenho ambiental e o econômico (Dutra \& Parente, 2018; Fasolin et al., 2014), muito embora haja aquelas com nível significativo de evidenciação ambiental que obtiveram satisfatório desempenho econômico (Beuren et al., 2013). 


\section{CONCLUSÕES}

O presente estudou verificou a relação existente entre a qualidade da informação ambiental e a rentabilidade de empresas do setor de energia elétrica pertencentes à B3 listadas no Índice de Sustentabilidade Empresarial (ISE). Analisou a qualidade da informação na divulgação dos relatórios de sustentabilidade, nos quais foram utilizados como parâmetro os indicadores de desempenho Econômico das Diretrizes G3.1, G4.0 e Standards da Global Reporting Initiative (GRI) de um grupo de empresas do ramo de energia elétrica do Brasil listadas no ISE.

Quanto ao objetivo geral, primeiramente procedeu-se a análise do IAC das empresas da amostra. Conclusa essa etapa, sucedeu-se à diagnose da Regressão quantílica simples. Ao confrontar o conteúdo das informações ambientais divulgadas por meio dos relatórios ambientais com as informações dos relatórios contábeis obrigatórios - Demonstrações do Resultado do Exercício (DRE), Demonstração do Valor Adicionado (DVA), Balanço Patrimonial (BP), Notas Explicativas (N.E) e Relatório de Sustentabilidade (RS) - para obter o índice de acurácia, percebeu-se que as empresas apresentaram dificuldades no entendimento e apresentação das orientações IP GRI.

Esse fato chamou a atenção, pois a maioria dos indicadores são regidos $e$ fundamentados por normas contábeis, e as empresas são familiarizadas com elas. Os resultados obtidos com relação à qualidade das informações ambientais demonstraram que a maioria das empresas analisadas divulgam um considerável percentual de evidenciação, estando elas entre médio e alto índice de acurácia.

A partir dos resultados dos IACs das instituições verificou-se, por meio de estimações resultantes da regressão quantílica, a relação existente entre a qualidade da informação ambiental e a rentabilidade de empresas do setor de energia elétrica listadas no ISE. Constatou-se que as organizações analisadas divulgam suas ações sustentáveis com qualidade, mas estas não influenciam na rentabilidade, corroborando os achados de Dutra e Parente (2018) e Fasolin et al. (2014) e parcialmente os resultados de Beuren et al. (2013).

A pesquisa apresenta limitações: a restrição de acesso a dados e quantitativos de empresas que divulgam relatórios de sustentabilidade referentes ao período 2014-2017; e a ausência de uniformidade entre os Relatórios de Sustentabilidade divulgados pelas instituições analisadas. Diante disso, recomenda-se para futuros estudos ampliar o período e a amostra, considerando grupos de empresas participantes e não participantes do ISE que utilizam dados em painel com efeitos fixos ou variáveis para melhor captar e compreender as particularidades de cada empresa analisada. Ademais, empregar outros indicadores a fim de verificar a relação com a evidenciação de informações sociais e ambientais. 
Ressalta-se que os achados da pesquisa se limitam apenas à amostra analisada, por isso os resultados não devem ser generalizados. Ainda, que as empresas estudadas podem ter tido mais ações de natureza socioambiental, entretanto não as divulgaram.

\section{REFERÊNCIAS}

Agência Nacional de Energia Elétrica (2006). Manual de elaboração do relatório anual de responsabilidade socioambiental das empresas de energia elétrica. http://www2.aneel. gov.br/aplicacoes/leitura_arquivo/default.cfm?idaplicacao $=43$

Antunes, M. A., \& Procianoy, J. L. (2003). Os efeitos das decisões de investimentos das empresas sobre os preços de suas ações no mercado de capitais. Revista de Administração da Universidade de São Paulo, 38(1).

Bansal, P., \& Clelland, I. (2004). Talking trash: Legitimacy, impression management, and unsystematic risk in the context of the natural environment. Academy of Management Journal, 47(1), 93-103.

Barth, M. E., McNichols, M. F., \& Wilson, G. P. (1997). Factors influencing firms' disclosures about environmental liabilities. Review of Accounting Studies, 2(1), 35-64.

Beato, R. S., Souza, T. S., \& Parisotto, I. R. (2009). Rentabilidade dos índices de sustentabilidade empresarial em bolsa de valores: Um estudo ISE/BOVESPA. Revista de Administração e Inovação, 6(3), 108-127.

Ben, F. (2005). Evidenciação de informações ambientais pelas empresas gaúchas. Revista Universo Contábil, 1(3), 63-80.

Beuren, I. M., Nascimento, S. D., \& Rocha, I. (2013). Nível de evidenciação ambiental e desempenho econômico de empresas: Aplicando a análise envoltória de dados. Future Studies Research Journal, 5(1), 198-226.

BM\&FBovespa (2019). Índice de Sustentabilidade Empresarial (ISE). http://www.bmfbovespa.com.br/pt_br/produtos/indices/indices-de-sustentabilidade/indice-de-sustentabilidade-empresarial-ise.htm

Braga, C., Sampaio, M. S. A., dos Santos, A., \& da Silva, P. P. (2011). Fatores determinantes do nível de divulgação ambiental no setor de energia elétrica no Brasil. Advances in Scientific and Applied Accounting, 4(2), 230-262.

Buhr, N., \& Freedman, M. (2001). Culture, institutional factors and differences in environmental disclosure between Canada and the United States. Critical Perspectives on Accounting, 12(3), 293-322. 
Cavalcante, L. R. M. T., Bruni, A. L., \& Costa, F. J. M. (2007). Sustentabilidade empresarial e desempenho corporativo: Uma análise do mercado brasileiro de ações. Anais do Encontro Nacional da Associação Nacional dos Programas de Pós-graduação em Administração, Rio de Janeiro, 31.

Carneiro, C. M. B., Silva, P. P., Santos, A., \& Santos, G. P. (2012). A divulgação ambiental no setor de energia elétrica brasileiro. Anais do Congresso Nacional de Excelência em Gestão, Rio de Janeiro, 8.

Castilho, R. A. A., \& Vasconcelos, F. C. W. (2016). As diretrizes GRI e o perfil histórico de publicação de relatórios de sustentabilidade no Brasil e no mundo. Anais do Simpósio Internacional de Gestão de Projetos, Inovação e Sustentabilidade, São Paulo, 5.

Conselho Empresarial Brasileiro para o Desenvolvimento Sustentável. (2017). O que é GRI? Entenda tudo!. http://cebds.org/blog/o-que-e-gri/\#.WbCYB+SGPIU

Cormier, D., \& Magnan, M. (2015). The economic relevance of environmental disclosure and its impact on corporate legitimacy: An empirical investigation. Business Strategy and the Environment, 24(6), 431-450.

Dantas, J. A., Zendersky, H. C., Santos, S. C., \& Niyama, J. K. (2005). A dualidade entre os benefícios do disclosure e a relutância das organizações em aumentar o grau de evidenciação. Revista Economia \& Gestão, 5(11), 56-76.

Darnall, N., \& Carmin, J. (2005). Greener and cleaner? The signaling accuracy of US voluntary environmental programs. Policy Sciences, 38(2-3), 71-90.

Dias, C. P., Lima Filho, R. N., Pinheiro, F. M. G., Silva, T. B. D. J., \& Moreira, R. D. C. (2015). Evidenciação de informações socioambientais, teoria da legitimidade e isomorfismo: Um estudo com mineradoras brasileiras. Revista de Gestão e Contabilidade da UFPI, 1(1).

Dutra, R. S., \& Parente, P. H. N. (2018). Desempenho ambiental e econômico: Uma análise nas empresas brasileiras. Humanas Sociais \& Aplicadas, 8(21).

Elijido-Ten, E., Kloot, L., \& Clarkson, P. (2010). Extending the application of stakeholder influence strategies to environmental disclosures: An exploratory study from a developing country. Accounting, Auditing \& Accountability Journal, 23(8), 1032-1059.

Farias, K. T. R. (2009). A relação entre divulgação ambiental, desempenho ambiental e desempenho econômico nas empresas brasileiras de capital aberto: Uma pesquisa utilizando equações simultâneas (Tese de doutorado, Universidade de São Paulo). 
Fasolin, L. B., Kaveski, I. D. S., Chiarello, T. C., Marassi, R. B., \& Heinn, N. (2014). Relação entre o índice de sustentabilidade e os indicadores econômico-financeiros das empresas de energia brasileiras. Revista Eletrônica em Gestão, Educação e Tecnologia Ambiental, 18(2), 955-981.

Fidelis, J. R. F., \& Cândido, C. M. (2006). A administração da informação integrada às estratégias empresariais. Perspectivas em ciência da informação, $11(3)$.

Figueiredo, P. A. R., Nobre, L. H. N., Nobre, F. C., Siqueira, E. S., \& de Macêdo, Á. F. P. (2017). Disclosure ambiental e rentabilidade: Um estudo com empresas do setor de eletrodomésticos listadas na bovespa. Revista Gestão em Análise, 6(1/2), 159-176.

Furtado, L. L., Antonovz, T., Correa, M. D., Silva, O. A. D. P., \& Panhoca, L. (2019). Relação entre Sustentabilidade e Inovação: Uma análise da legitimidade organizacional das empresas do setor elétrico brasileiro. Revista Catarinense da Ciência Contábil, 18, 2807.

Garcia, S., Cintra, Y. C., Souza Ribeiro, M., \& Dibbern, B. R. S. (2015). Qualidade da divulgação socioambiental: Um estudo sobre a acurácia das informações contábeis nos relatórios de sustentabilidade. Revista Contemporânea de Contabilidade, 12(25), 67-94.

Global Reporting Initiative. (2006). Diretrizes para relatório de sustentabilidade. versão 3.O. https://www.globalreporting.org/resourcelibrary/GRI-G3-Brazilian-Portuguese-Reporting-Guidelines.pdf

Global Reporting Initiative. (2011). Diretrizes para Relatório de Sustentabilidade. https:// www.globalreporting.org/resourcelibrary/Brazilian-Portuguese-G3.l.pdf

Global Reporting Initiative. (2013). Diretrizes para relatório de sustentabilidade. https:// www.globalreporting.org/resourcelibrary/Brazilian-Portuguese-G4-Part-One.pdf

Gomes, F. P., \& Tortato, U. (2011). Adoção de práticas de sustentabilidade como vantagem competitiva: Evidências empíricas. Revista Pensamento Contemporâneo em Administração, 5(2), 33-49.

Hoti, S., McAleer, M., \& Pauwels, L. L. (2007). Measuring risk in environmental finance. Journal of Economic Surveys, 21(5), 970-998.

Janiszewski, V. J., Carrascoso, L. A., Felix Júnior, L. A., Lagioia, U. C. T., \& Oliveira, M. F. J. (2017). Relação da Teoria da Sinalização com o Desempenho das Empresas a partir dos seus Indicadores de Performance de Divulgação Voluntária. Revista Contabilidade e Controladoria, 9(2). 
Klann, R. C., \& Beuren, I. M. (2011). Características de empresas que influenciam o seu disclosure voluntário de indicadores de desempenho. BBR-Brazilian Business Review, 8(2), 96-118.

Koenker, R. (2018). Quantreg: Quantile Regression. R package version 5.38. https:// CRAN.R-project.org/package $=$ quantreg

Koenker, R. (2005) Quantile regression. Cambridge University.

Lozano, R. (2013). Sustainability inter-linkages in reporting vindicated: A study of European companies. Journal of Cleaner Production, 51, 57-65.

Lucena, S. L., \& Travassos, S. K. M. (2013). Análise comparativa dos relatórios de sustentabilidade do Global Reporting Initiative com ênfase nas empresas de capital aberto com atuação no Brasil. Veredas Favip-Revista Eletrônica de Ciências, 2(1-2).

Machado, M. R., Machado, M. A. V., \& Corrar, L. J. (2009). Desempenho do índice de sustentabilidade empresarial (ISE) da Bolsa de Valores de São Paulo. Revista Universo Contábil, 5(2), 24-38.

Nossa, V. (2002). Disclosure ambiental: Uma análise do conteúdo dos relatórios ambientais de empresas do setor de papel e celulose em nível internacional (Tese de Doutorado, Universidade de São Paulo).

Ohlson, J. A., \& Kim, S. 2015. Linear valuation without OLS: The Theil-Sen estimation approach. Review Accounting Studies, 20(1):395-435.

Peixoto, E. P. A., Santos, R. R., \& Luz, J. R. M. (2017). Relação da evidenciação dos gastos ambientais e desempenho econômico-financeiro de empresas potencialmente poluidoras do Brasil. Revista de Contabilidade do Mestrado em Ciências Contábeis da UERJ, 22(3), 36-53.

Porter, M. E., \& Van der Linde, C. (1995). Toward a new conception of the environment-competitiveness relationship. Journal of economic perspectives, 9(4), 97-118.

Potrich, R., Sabadin, M., Angonese, R., \& Pereira, A. D. S. (2017). Empresas potencialmente poluidoras: Determinantes que influenciam a divulgação voluntária de informações ambientais. Revista Ambiente Contábil, 9(2), 41-59.

Rodrigues, M. (2014). Contrasting realities: Corporate environmental disclosure and stakeholder-released information. Accounting, Auditing \& Accountability Journal, 27(1), 119-149. 
Rosa, F. D., Lunkes, R. J., Hein, N., Vogt, M., \& Degenhart, L. (2014). Analysis of the determinants of disclosure of environmental impacts of Brazilian companies. Global Advanced Research Journal of Management and Business Studies, 3(6), 249-266.

Rosa, F. S., Ensslin, S. R., Ensslin, L., \& Lunkes, R. J. (2011). Gestão da evidenciação ambiental: Um estudo sobre as potencialidades e oportunidades do tema. Engenharia Sanitária Ambiental, 16(1), 157-166.

Rover, S., Borba, J. A., Murcia, F. D. R., \& Vicente, E. F. R. (2008). Divulgação de informações ambientais nas demonstrações contábeis: Um estudo exploratório sobre o disclosure das empresas brasileiras pertencentes a setores de alto impacto ambiental. Revista de Contabilidade e Organizações, 2(3), 53-72.

Rover, S., Tomazzia, E. C., Murcia, F. D. R., \& Borba, J. A. (2012). Explicações para a divulgação voluntária ambiental no Brasil utilizando a análise de regressão em painel. Revista de Administração, 47(2), 217-230.

R Core Team (2020). R: A language and environment for statistical computing. R Foundation for Statistical Computing. https://www.R-project.org/

Santana, L. M., Góis, A. D., Luca, M. M. M., \& Vasconcelos, A. C. (2015). Relação entre disclosure socioambiental, práticas de governança corporativa e desempenho empresarial. Revista Organizações em Contexto, 11(21), 49-72.

Sato, K. H., Silva, W., Nogas, P., \& Yamashiro, A. (2010). Sustentabilidade e responsabilidade social: Análise do desempenho do índice de sustentabilidade empresarial. Perspectivas Contemporâneas, 5, 157-177.

Spence, A. M. (1973). Job market signalling. Quarterly Journal of Economics, 87(3), 355- 374.

Spence, C., Husillos, J., \& Correa-Ruiz, C. (2010). Cargo cult science and the death of politics: A critical review of social and environmental accounting research. Critical Perspectives on Accounting, 21(1), 76-89.

Rezende, I. (2007). Um estudo sobre o desempenho financeiro do Índice BOVESPA de Sustentabilidade Empresarial. Anais do Encontro da Associação Nacional dos Programas de Pós-Graduação em Administração, Rio de Janeiro, 31.

Silva, C. R. M., Viana Júnior, D. B. C., \& Lima, D. S. V. R. (2017). A teoria do disclosure à luz da teoria da sinalização: Implicações na continuidade da firma. Revista Contabilidade, Ciência Da Gestão E Finanças, 5(3), 138-151. 
Silva, L. R., Mello, J. A. V. B., Gonze, N. C., \& Orrico Filho, R. D. (2015). Construção de um índice-padrão e análise da performance financeira das empresas de capital aberto que atuam no setor de exploração de Rodovias. Scientia Plena, 11(3).

Sueyoshi, T., \& Goto, M. (2009). Can environmental investment and expenditure enhance financial performance of US electric utility firms under the clean air act amendment of 1990? Energy Policy, 37(11), 4819-4826.

Tarr, G. (2012). Small sample performance of quantile regression confidence intervals. Journal of Statistical Computation and Simulation, 82(1), 81-94.

Como citar este artigo:

\section{ABNT}

SANTOS, Ana Lúcia dos; PRADO, Alexsandro Gonçalves da Silva; MOREIRA, Caritsa Scartaty; SOARES, José Mauro Madeiros Veloso. Qualidade da informação ambiental versus rentabilidade de empresas do setor elétrico listadas no ISE. RACE, Revista de Administração, Contabilidade e Economia, v. 19, n. 3, p. 537-566, mês/dez. 2020. Disponível em: http://editora.unoesc.edu.br/index.php/race. Acesso em: dia/mês/ano.

\section{APA}

Santos, A. L., Prado, A. G. S., Moreira, C. S., \& Soares, J. M. M. V. (ano). Qualidade da informação ambiental versus rentabilidade de empresas do setor elétrico listadas no ISE. RACE, Revista de Administração, Contabilidade e Economia, 19(3), 537-566. http://editora.unoesc.edu.br/index.php/race 